\title{
LA TRANSFORMACIÓN FARMER. \\ COLONIZACIÓN AGRÍCOLA Y CRECIMIENTO \\ ECONÓMICO EN LA PROVINCIA DE SANTA FE \\ DURANTE LA SEGUNDA MITAD DEL SIGLO XIX
}

de Juan Luis Martirén,

Buenos Aires, Prometeo / Asociación Argentina de

Historia Económica, 266 pp.

SOL LANTERI

Instituto de Historia Argentina y Americana «Dr. Emilio

Ravignani» - CONICET / Universidad de Buenos Aires

Esta obra constituye la versión acortada y revisada de la pesquisa doctoral del autor, que fue defendida en la UNicen en el año 20I3, merecedora con justicia del Premio a la Mejor Tesis Doctoral en Historia Económica, en el marco del V Concurso de la Asociación Argentina de Historia Económica merced a la cual se publica.

De prosa clara y cuidada, su objetivo central es analizar un proceso de crucial importancia para la historia económica de la región pampeana y de otras latitudes como fue el proceso de colonización agrícola en la provincia de Santa Fe durante la segunda mitad del siglo xix. De hecho, siendo la provincia menos desarrollada de aquella área hacia mediados de la centuria y habiendo sido instaladas las tres primeras colonias -Esperanza, San Carlos y San Gerónimo- a partir de 1856, se multiplicaron de forma exponencial a 400 con más de un millón de hectáreas sembradas hacia 1895. Martirén estudia «en filigrana» cómo se dio entonces ese espectacular despegue en apenas cuarenta años mediante distintos temas interrelacionados con distintas temporalidades en función de los temas abordados en cada capítulo.

La tesis general del libro es que el sistema productivo santafecino constituyó un "caso testigo" de expansión agraria para las provincias pampeanas vecinas en los prolegómenos de la Argentina agrícola del siglo xx. Es más, en propias palabras del autor: «La gran transformación experimentada por esta provincia en tan solo cuatro décadas, probablemente haya sido uno de los ejemplos más interesantes de reconversión productiva en el mundo capitalista» (p. 2I).

El libro no sólo revisita temas anteriormente estudiados por la bibliografía 
especializada, sino que aborda otros que habían sido poco explorados hasta ahora, como por ejemplo, los nuevos sistemas de propiedad de la tierra y el diferencial acceso a la misma -generadores o no de una mayor igualdad y movilidad social-, interrogantes claves en el entendimiento del desarrollo agropecuario pampeano coetáneo y posterior; la relación entre las economías criolla y de las colonias de impronta étnica europea; las estrategias de los empresarios para el desarrollo productivo, etc. A su vez, reinterpreta las causas, el desarrollo y el corolario de los diversos procesos vinculados a la colonización agrícola, considerando regularmente la sociedad criolla en la que se insertó -y que a la vez transformó- y la economía nacional que coadyuvó a conformar de forma dinámica y protagonista.

Además del valor y la audacia de emprender una investigación de tan largo aliento y dificultad en virtud de las obras clásicas existentes sobre el tema, vale destacar el material heurístico usado por el autor, que es realmente apabullante en cantidad, calidad y originalidad, habiendo examinado una gran variedad de archivos -locales, regionales, provinciales y nacionales-, como el del Museo Histórico de Humbolt, donde se consultó el fondo del molino Milesi, no disponible hasta entonces. Las fuentes empleadas, públicas, privadas y de distinto alcance geográfico, se encuentran de- bidamente trianguladas, como los censos nacionales de 1869 y 1895 , planos y mapas provinciales y de las colonias, ministerio de gobierno, libros de contaduría y hacienda del Ministerio de Hacienda provincial y del Banco provincial de Santa Fe, juzgado de paz, protocolos de escribanos, boletos de compraventa, asientos contables y documentación privada de algunos particulares como Guillermo Lehman y otras empresas colonizadoras y empresarios, múltiples recopilaciones de leyes, memorias y relatos oficiales coetáneos, informes consulares de la Foreing Office británica, publicaciones periódicas y diversas obras de época. La bibliografía general y específica es asimismo apropiada y vasta, dialogando con los principales debates internacionales en curso. El autor realiza una constante explicitación de los alcances y limitaciones de la información de las fuentes utilizadas y de la metodología implementada, lo que le permite una reconstrucción honesta y rigurosa de los temas y problemas abordados. Otro aspecto a subrayar en este sentido es la construcción de amplias series de datos sobre precios, rentabilidad empresaria, productividad factorial y distribución de la riqueza. Por citar un ejemplo, sólo en el Cap. 3 se trabajó, entre otras fuentes, con 3.625 transacciones de compraventa privadas de tierras en las colonias agrícolas. Esta información, además de estar debidamente procesada, se encuentra dispo- 
nible en los Apéndices, que cuentan con series de precios de tierras y de tierras de pastoreo en las colonias -según clases de éstas- del hinterland santafecino y rosarino considerando ańo, cantidad de operaciones, superficie, precio en pesos oro total y por hectárea, promedio de hectáreas por operación, etc., apoyando las argumentaciones y conclusiones del libro a la vez que constituyendo una eventual base de datos para investigaciones futuras.

Una de las tesis centrales de Martirén es que la economía farmer emergente de la colonización agrícola fue un punto de inflexión en la historia económica y social provincial, adquiriendo protagonismo a partir de la década de I870 y generando una radical transformación de su campaña. Así, atiende a cuatro variables explicativas centrales para responder sus interrogantes anclado en una lectura holista que contempla las transformaciones estructurales de su objeto de estudio, a saber: la formación y evolución del mercado inmobiliario rural, la praxis empresaria de las colonias, la acumulación y distribución de la riqueza inmobiliaria en las colonias y la productividad de la economía farmer.

De esta forma, organiza la obra en seis capítulos, los dos primeros más generales sobre las características económicas de la provincia, que permiten situar en contexto al lector, y los cuatro restantes sobre aspectos particulares atenidos al proceso de colonización agrícola, eje de su estudio. En el capítulo I, «La economía santafecina en el siglo XIX», se desarrolla la evolución económica provincial en el largo plazo, desde la época colonial hasta fines del siglo XIx, atendiendo al impacto de las guerras civiles y los cambios producidos desde i850s a nivel demográfico y de modernización económica. El capítulo II, «Los números de la colonización agrícola», dimensiona con guarismos precisos el proceso de colonización agrícola mediante cortes temporales por decenio que permiten vislumbrar en detalle los cambios originados por el proceso de colonización, considerando los obstáculos originales de las primeras colonias, el crecimiento económico en virtud de la guerra del Paraguay, los intentos expansivos hacia el oeste y el boom colonizador de las décadas de I880 y I890. Por su parte, en el capítulo III «La emergencia de un nuevo mercado de tierras rural (I860-I895)», se estudia de forma pionera la formación y evolución del mercado inmobiliario rural en la provincia de Santa Fe -siendo justamente la mercantilización del factor una de las principales modificaciones del proceso estudiado- considerando sus particularidades regionales y la existencia de mercados diferenciales en las colonias y las áreas de pastoreo de la economía criolla. Una vez desarrollados estos puntos, el capítulo IV, «Los empresarios de la colonización (I860-I895)", aborda otra variable de 
estudio novedosa, como es el análisis de actores centrales como los empresarios, a partir de cuatro casos de estudio principales que le permiten al autor iluminar más las etapas constitutivas del proceso que sus propias particularidades. El capítulo $\mathrm{V}$, «La riqueza inmobiliaria en las colonias agrícolas (I864-I884)», examina con profundidad una línea analítica con antecedentes en la historiografía rural pampeana pero novedosa para su objeto de estudio como los patrones de acumulación y distribución de la riqueza en las colonias, que cambiaron con creces el desigual y característico acceso a la propiedad de la tierra existente. Finalmente, el capítulo vI, «La productividad factorial en la economía farmer (I865-I895)", examina y cuantifica con detalle los costos de producción y la productividad factorial de la tierra, el trabajo y el capital en todas las colonias estudiadas y el valor del trigo, su principal producto, para estimar la evolución de su productividad en esa economía, lo que le permite al autor sopesar con rigor el origen factorial y temporal del gran crecimiento productivo de ese cultivo.
Entre las principales conclusiones que arriba el estudio puede mencionarse la importancia de la tierra además del capital en el proceso de expansión agrícola santafecino hasta su cenit ca. I895, sobre todo en zonas de más antigua colonización y la vinculación de la crisis del sistema farmer con el ciclo de conflictividad social desatado a partir de I890, especialmente en el centro oeste provincial.

En suma, el libro se inserta plenamente en el debate sobre los modelos de desarrollo del capitalismo agrario internacional en base a la revisión del rol estatal, los agentes colonizadores y el mercado de tierras dentro del estudio del desarrollo agropecuario y social moderno de la provincia de Santa Fe, aportando desde la historia económica y de empresas, en un período crucial de "la gran transformación» vernácula como fue la segunda mitad del siglo xIx y su impacto en procesos globales en la mediana y larga duración, a la vez que manifiesta la solidez y maduración de una investigación y de un investigador en mucha mayor medida que la «mies» objeto de su estudio. 